Thorax (1976), 31, 391.

\title{
Pericardiectomy in children
}

\author{
R. L. VAN DER HORST and B. T. LE ROUX \\ Thoracic Surgical Unit, Wentworth Hospital, and Department of Thoracic Surgery, \\ University of Natal, South Africa
}

\begin{abstract}
van der Horst, R. L. and le Roux, B. T. (1976). Thorax, 31, 391-393. Pericardiectomy in children. Thirty-five children under 16 years of age were prepared for pericardiectomy on account of constrictive pericarditis; three died in the immediate preparatory period. Pericardiectomy was undertaken in 32; in 28 the cause was tuberculous. The purpose of this report is to draw attention to the high incidence of constrictive pericarditis in African children in Natal.
\end{abstract}

During a 13-year period (1963-75) pericardiectomy for constrictive pericarditis was undertaken in 227 patients, of whom $32(14 \%)$ were under 16 years of age. Two other children died in the immediate preparatory period and a third in the operating theatre immediately before induction of anaesthesia. From a scrutiny of the literature on pericardiectomy for constrictive pericarditis it seems that our $14 \%$ incidence in children is very high. Published reports from large paediatric centres relate to only small numbers of children (Shea, Kirklin, and DuShane, 1957; Roshe and Shumacker, 1959; Simcha and Taylor, 1971; Somers et al., 1971; Bitar et al., 1972; Shrivastava, Prusty, and Tandon, 1973; Greenwood et al., 1974; Strauss, Santa-Maria, and Goldring, 1975). None of these reports includes more than 10 children, and not all were submitted to surgery. In many countries tuberculosis is largely controlled. In Natal in the Republic of South Africa, tuberculosis remains common, often assumes a florid form in the African population, and is still a common cause of death in children. Septic (non-tuberculous) pericarditis can cause cardiac constriction or may complicate pericardiocentesis for tamponade in patients with tuberculous pericardial effusion and contribute to the ultimate development of constriction. Rarely, malignant tumours in children may present primarily with the clinical features of constrictive pericarditis.

\section{THE PATIENTS}

Thirty-five children were prepared for or had the operation of pericardiectomy because of the clinical, radiographic, and (in many) angiographic features of constrictive pericarditis. The youngest were two girls aged 1 year, and the oldest four children aged 15 years; eight were aged 5 years or younger, and 18 of the 35 were 10 years old or younger. There were 14 girls and 21 boys. Thirty-one were African, three Asiatic, and one Mulatto. In 28 the diagnosis of tuberculosis was established; in five with cardiac constriction, tuberculosis was not established and the clinical course of their illness was that of septic nontuberculous pericarditis; two had malignant intrapericardial tumours-lymphosarcoma in one and adenocarcinoma in the other. All had in common the features of constrictive pericarditis; children with pericardial effusion from tuberculosis or pericardial sepsis who underwent pericardial drainage are not included, nor are those with the clinical or haemodynamic evidence of constriction in whom an operation was not considered necessary.

Those in whom the diagnosis of tuberculous pericarditis was established or suspected on reasonable grounds received antituberculosis therapy for a mean period of four months before operation, some for as long as one year. Generalized lymphadenopathy was rare. In two patients, a lymph node biopsy did not establish the diagnosis of tuberculosis, the node showing only the features of reactive hyperplasia. Evidence of systemic or pulmonary tuberculosis was unusual. There was an associated pleural effusion in eight children; in 10, the natural history of the disease included a period during which the cardiac silhouette was globular; in seven of this group of 10 , pericardiocentesis yielded liquid $(40-600 \mathrm{ml})$, and in three the heart shadow became smaller with the development of the signs of constriction. One child aged 6 years had miliary tuberculosis with 
pleural and pericardial effusions and was treated in hospital on antituberculosis drugs for three months with such marked clinical improvement that he was transferred elsewhere. Seven months later he was readmitted in a moribund state and died on the operating table while being prepared for anaesthesia. The diagnosis of constrictive pericarditis was confirmed at necropsy. In another child aged 14 years, the signs of pericardial constriction developed after repeated pericardiocenteses and four months of antituberculosis chemotherapy; death occurred immediately before operation. At necropsy severe and active generalized tuberculosis was present, involving the liver, lungs, pericardium, and spleen.

Ascites was a cause of discomfort and respiratory embarrassment in a number of children in whom abdominal paracentesis was undertaken before operation.

\section{THE OPERATION}

The approach in one-third of the patients was a left thoracotomy and in two-thirds a vertical sternotomy. In all, there was evidence at operation of severe cardiac constriction. In 19 children there was a considerable volume of caseous material between the layers of pericardium. The pericardium was thick and fibrotic, and adherent to the myocardium, and in many instances there was no well defined plane of cleavage. In most, the heart was evenly constricted; in a few, constriction involved the right heart more obviously than the left.

In one patient a thick fibrotic band extended across the right atrium and outflow tract of the right ventricle, with right ventricular outflow obstruction as the obvious result. Before operation this child had haemodynamic investigations without the diagnosis of constrictive pericarditis being considered. Presentation was with the clinical features of severe right ventricular outflow tract obstruction, tricuspid incompetence, and right heart failure with systemic congestion. At cardiac catheterization the right ventricular pressure was $176 / 14-18 \mathrm{mmHg}$ with severe pulsus alternans present in the RV pressure tracing.

In the five children with septic pericarditis, in addition to pericardial thickening and cardiac constriction the pericardial sac contained loculi of pus, fibrinous clot, and multiple adhesions between the pericardial layers.

In all patients the chambers of the heart, the root of the great vessels, and the cavae were freed of restrictive tissue, and in one patient right ven- tricular outflow tract repair was undertaken. Peri- $\frac{\vec{\Rightarrow}}{\overrightarrow{0}}$ cardial calcification was observed in five children, $\frac{\sqrt{+}}{\sigma}$ of whom the youngest was aged 3 , and in one $\frac{-}{-}$ there was associated myocardial calcification.

\section{RESULTS}

Of 35 children 11 died. Of 32 submitted to an. operation, eight died, four in early convalescence $\overrightarrow{\vec{\omega}}$ and four later. Of 28 patients with establishedo tuberculous constrictive pericarditis, two died im-家 mediately before operation, three died in the early postoperative period (in two of these, constrictive tuberculous pericarditis was complicated by paracentesis-induced pericardial sepsis), and $\Theta$ one died four months after operation. Of five윽 children in whom septic pericarditis was respon- sible for the clinical features of pericardial con- $\rightarrow$ striction, one died in the immediate preoperativeo period, one died in the early postoperative period, $\stackrel{5}{?}$ and one died two months later. The child with $\overrightarrow{0}$ adenocarcinoma in the pericardium died in the early postoperative period and the child with? lymphosarcoma died some months later.

\section{DISCUSSION}

Constrictive pericarditis is in many countries rare disease, and although there have been many $\frac{3}{3}$ reports in the literature, most relate to adults. Pericardiectomy was first undertaken in a childo by Rehn (1920).

While the clinical and radiographic features of constrictive pericarditis are well known, distinc- $\frac{0}{x}$ tion from myocardial disease may be difficult. $\mathrm{A}_{\bar{\sigma}}^{\times}$ careful analysis of the electrocardiogram is often 3 . useful (Lewis, van der Horst, and Gotsman, 1971) while radioisotope cardiac pool scanning (Winship et al., 1970) and the haemodynamic and angio-o graphic features (Gotsman et al., 1972; Lewis and Gotsman, 1973) are classical.

Without successful operation constrictive pericarditis has a high mortality. Constrictive pericar-o ditis in a child who also has widely disseminated $N$ tuberculosis is a particularly difficult clinical problem, i.e., when to undertake a major surgicalo procedure in a child ill not only from pericardia 6 constriction but from disseminated tuberculosis. Antituberculosis chemotherapy does not preventes ingravescent constriction and does not necessarily control widely disseminated tuberculosis. Childrenō in whom pericardial constriction has been ade $\overrightarrow{\mathbb{D}}$ quately relieved by pericardiectomy are well, al- $\frac{\Omega}{\mathrm{D}}$ though usually not immediately after operation. 


\section{REFERENCES}

Bitar, J. G., Nassif, S. I., Khuri, S. F., and Nassar, V. H. (1972). Constrictive pericarditis in a child presenting as liver cirrhosis. Lebanese Medical Journal, 25, 291.

Gotsman, M. S., le Roux, B. T., Rogers, N. M. A., van der Horst, R. L., and Winship, W. S. (1972). Immediate haemodynamic results of pericardiectomy. South A frican Medical Journal, 46, 3.

Greenwood, R. D., Rosenthal, A., Cassady, R., Jaffe, N., and Nadas, A. S. (1974). Constrictive pericarditis in childhood due to mediastinal irradiation. Circulation, 50, 1033.

Idriss, F. S., Nikaidoh, H., and Muster, A. J. (1974). Constrictive pericarditis simulating liver disease in children. Archives of Surgery, 109, 223.

Lewis, B. S. and Gotsman, M. S. (1973). Left ventricular function in systole and diastole in constrictive pericarditis. American Heart Journal, 86, 23.

, van der Horst, R. L., and Gotsman, M. S. (1971). Diagnostic electrocardiographic patterns in Bantu myocardiopathy and constrictive pericarditis. South A frican Medical Journal, 45, 1110.

Rehn, L. (1920). Über pericardiale Verwachsungen. Medizinische Klinik, 16, 1991. Quoted by Roshe, J. and Schumacker, H. B. Jr. (1959), p. 1155.

Roshe, J. and Shumacker, H. B. Jr. (1959). Pericardiectomy for chronic cardiac tamponade in children. Surgery, 46, 1152.
Shea, D. W., Kirklin, J. W., and DuShane, J. W. (1957). Chronic constrictive pericarditis in children. American Journal of Diseases of Children, 93, 430 .

Shrivastava, S., Prusty, S., and Tandon, R. (1973). Constrictive pericarditis in children. Indian Pediatrics, 10, 585 .

Simcha, A. and Taylor, J. F. N. (1971). Constrictive pericarditis in childhood. Archives of Disease in Childhood, 46, 515.

Somers, K., de Buse, P. J., Patel, A. K., d'Arbella, P. G., and Grigg, G. L. (1971). Childhood tuberculous pericarditis. Chest, 60, 22.

Strauss, A. W., Santa-Maria, M., and Goldring, D. (1975). Constrictive pericarditis in children. American Journal of Diseases of Children, 129, 822.

Winship, W. S., Houlder, A. E., van der Horst, R. L., and Gotsman, M. S. (1970). Radioisotope cardiac pool scanning in children. Pediatrics, 45, 996.

Requests for reprints to: Professor B. T. le Roux, The Thoracic Surgical Unit, Wentworth Hospital, Natal, South Africa. 